\title{
Fabrication and Characterization of a Tubular Solid Oxide Fuel Cell with Impregnated Perovskite Electrodes
}

\author{
K. Nowicki, Mei Wang and J. T. S. Irvine \\ School of Chemistry, University of St Andrews, St Andrews, Fife, KY16 9ST, UK
}

The tubular cells were produced by a simple and inexpensive method, suitable for mass production. A porous YSZ backbone was co-cast with a thin layer of YSZ electrolyte over it. After rolling in tubular shape and co-sintering, the porous backbone was impregnated with functional perovskite materials, the nickel doped lanthanum calcium titanate LCNT $\left(\mathrm{La}_{0.43} \mathrm{Ca}_{0.37} \mathrm{Ni}_{0.06} \mathrm{Ti}_{0.94} \mathrm{O}_{3-\gamma}\right)$ for the fuel side and the lanthanum strontium ferrite LSF $\left(\mathrm{La}_{0.8} \mathrm{Sr}_{0.2} \mathrm{FeO}_{3}\right)$ for the air electrode.

The LCNT perovskite was proposed as the alternative fuel electrode due to its mixed ionic and electronic conductivity (MIEC) properties and catalytical activity supplemented by exsolved $\mathrm{Ni}$ nanoparticles. The electrochemical poling at high potential, so-called 'switching', can increase the activity of LCNT due to facilitated reduction and exsolution. After switching at $2.1 \mathrm{~V}$ for $2 \mathrm{~min}$, the tubular cell performance in fuel cell mode increased threefold. The impedance analysis indicated a reduction of ohmic and polarisation resistance on the whole frequency range and facilitated electrode kinetics under applied voltage.

\section{Introduction}

For the solid oxide tubular cells, successful preparation has been accomplished by a tape casting and co-sintering method, using LSM-YSZ and LCNT-YSZ ceramic composite as electrodes and YSZ as the electrolyte (1). Layers were cast separately, followed by lamination. After rolling into a tubular shape, the assembly was co-sintered in a single thermal step. The cells had good activity, stability and redox resistance due to tubular design and fully ceramic electrodes. Additionally, a thermal shock resistance test showed that the cell was resistant to rapid temperature changes. The co-sintering was limited to $1350{ }^{\circ} \mathrm{C}$, to avoid the reaction between the electrode and electrolyte. Low sintering temperature brought concerns about the quality of the YSZ electrolyte. The SEM analysis showed a small number of closed pores and a small size of YSZ grains. On the other hand, the $1350{ }^{\circ} \mathrm{C}$ is relatively high for sintering of the LSM electrode. Although A-site deficiency was used in LSM to decrease its reactivity with YSZ (3), the high-temperature sintering is causing the coarsening problem of LSM, leading to a decreased LSM-YSZ electrode performance (4).

In this work, the production method was further simplified and improved. A co-casting method was applied for producing porous YSZ backbone on YSZ electrolyte, which after sintering was impregnated with $\mathrm{La}_{0.8} \mathrm{Sr}_{0.2} \mathrm{FeO}_{3}$ (LSF) for oxygen electrode and 
$\mathrm{La}_{0.43} \mathrm{Ca}_{0.37} \mathrm{Ni}_{0.06} \mathrm{Ti}_{0.94} \mathrm{O}_{3-\gamma}$ ) (LCNT) for fuel electrode side. Compared with single casting and lamination of the cell components, co-casting produced a much more robust interface and allowed for easier control of the thickness of the electrolyte, which was reduced to 20 $\mu \mathrm{m}$. When the same material with electrolyte is used as the porous scaffold for electrode material, the co-sintering temperature of electrolyte and porous electrode scaffold can be increased to $1450{ }^{\circ} \mathrm{C}$, ensuring much better densification of electrolyte material. Furthermore, the co-sintering of the same material reduces the overlay of work related to tailoring the compatibility of shrinkage between the electrodes and electrolyte (2). While the impregnation method is used to deposit the active electrode materials on the porous scaffold, the electrode calcination temperature can be lowered to $850{ }^{\circ} \mathrm{C}$, alleviating the reaction between the electrode material and YSZ. The impregnation method allows for much larger flexibility in selecting materials and in tailoring their composition and microstructure (5). The advantage of using LSF as an oxygen electrode is its much better performance for oxygen reduction than LSM. Moreover, LSF has lower reactivity with YSZ than other well-performing oxygen electrode LSCF and does not contain carcinogenic cobalt (5).

The lanthanum calcium titanates (LCT) seem to be a good choice for the fuel electrode due to their n-type and good chemical and physical compatibility with YSZ electrolyte (6). However, LCT has low catalytic activity, limiting its utilization as a fuel electrode. The research community suggested an adsorption/dissociation process as the rate-determining step (RDS) in oxide fuel electrodes $(7,8)$, which in state of the art fuel electrodes is catalyzed by $\mathrm{Ni}$ (9). The kinetics of the $\mathrm{H}_{2}$ absorption/dissociation on oxide electrodes could be improved by metal catalysts deposited on their surface (7). In recent years, exsolution is found to be an elegant way to grow metallic catalyst in situ from perovskite oxides (10). The strong interaction of exsolved metal nanoparticles with the oxide matrix gives the materials superior stability and coking resistance. The exsolution process involves doping catalytically active transition metal ions into the perovskite B-site position; such cations are randomly distributed in a lattice and tend to be released as the metal particles on the perovskite surface in reducing conditions (e.g. 5\% $\mathrm{H}_{2} / \mathrm{Ar}$ ). Myung et al. (11) triggered the exsolution using electrochemical reduction by applying a high potential to the cell in the electrolysis mode, and a well-dispersed network of nickel nanoparticles was observed on nickel doped lanthanum calcium titanate LCNT $\left(\mathrm{La}_{0.43} \mathrm{Ca}_{0.37} \mathrm{Ni}_{0.06} \mathrm{Ti}_{0.94} \mathrm{O}_{3-\gamma}\right)$. The process has been termed "switching" and proved to be much more efficient and faster than chemical reduction.

\section{Experimental}

\section{Cell Manufacturing}

Tapes preparation. For the slurries preparation, the YSZ ceramic powders were mixed with organic ingredients, such as solvent, binder, plasticizers and dispersant, to obtain a castable slip that holds ceramic particles to produce the strong, homogeneous and elastic tape (12). The complete procedure of slurry preparation is given elsewhere (2).

For the electrodes' production, the ceramic powders were mixed with pore-formers (graphite and starch from rice) to provide a well-developed porous structure, while for the electrolyte, no pore-former was added. The tubular cell manufacturing involved co- 
sintering of the porous backbone with the co-cast YSZ electrolyte at $1450{ }^{\circ} \mathrm{C}$ for $5 \mathrm{~h}$. However, the pore former s' addition into porous backbone slurry could create differences in the shrinking profile between the electrolyte and electrodes during cells' sintering, which leads to the delamination and creation of defects in the cell. In order to obtain a defect-free cell, the shrinking profile and microstructure of the porous electrode were optimized by adjusting the size of ceramic particles in the tape slurry. For the ceramic backbone preparation, a mixture of the large and small size of YSZ was used, where the large powders were achieved by ball milling of the sintered YSZ pellets $\left(1450^{\circ} \mathrm{C}\right.$ for $\left.5 \mathrm{~h}\right)$ at $400 \mathrm{rpm}$ for $1 \mathrm{~h}$ and the small powders were purchased from (PI-KEM Limited). The large and small particle of YSZ were about $3.5 \mu \mathrm{m}$ and $1 \mu \mathrm{m}$, respectively.

Cell's manufacturing. The electrolyte tape was firstly cast on the Mylar film using the tape casting equipment. The doctor blade gap was adjusted to $100 \mu \mathrm{m}$. After drying overnight, the porous backbone was cast directly on the electrolyte tape with the doctor blade gap equal to $600 \mu \mathrm{m}$. The second electrode was cast separately with the same 600 $\mu \mathrm{m}$ gap of the doctor blade. After drying, the co-cast tape and the second electrode tape were laminated. Such assembly was cut into $27 \mathrm{~mm} \times 50 \mathrm{~mm}$ rectangles, rolled on an $8 \mathrm{~mm}$ steel bar to a tubular geometry and tied with electrolyte stripes. The cells' ends were covered with YSZ slurry to avoid leaking of impregnating solution between electrodes. The cell's sintering contained two stages, low-temperature calcination at $1000^{\circ} \mathrm{C}$ for $5 \mathrm{~h}$ followed by high-temperature sintering at $1450{ }^{\circ} \mathrm{C}$ for $5 \mathrm{~h}$.

Impregnation of electrodes. The $1 \mathrm{M}$ solution of $\mathrm{La}_{0.43} \mathrm{Ca}_{0.37} \mathrm{Ni}_{0.06} \mathrm{Ti}_{0.94} \mathrm{O}_{3-\gamma}$ was prepared by dissolving of high purity precursors $\mathrm{La}\left(\mathrm{NO}_{3}\right)_{2} \bullet 6 \mathrm{H}_{2} \mathrm{O}$ (Alfa Aesar, $>99.9 \%$ ), $\mathrm{Ca}\left(\mathrm{NO}_{3}\right)_{2} \bullet 4 \mathrm{H}_{2} \mathrm{O}$ (Alfa Aesar, $>99.0 \%$ ), $\mathrm{Ni}\left(\mathrm{NO}_{3}\right)_{2} \bullet 6 \mathrm{H}_{2} \mathrm{O}($ Acros, $>99 \%)$ and $\mathrm{C}_{6} \mathrm{H}_{18} \mathrm{~N}_{2} \mathrm{O}{ }_{8} \mathrm{Ti}$ (Alfa Aesar, 50\% w/w aq. soln.) into deionized water according to the stoichiometric proportions. Similarly, for preparation of $1 \mathrm{M} \mathrm{La} 0.8 \mathrm{Sr}_{0.2} \mathrm{FeO}_{3}$ solution, $\mathrm{La}\left(\mathrm{NO}_{3}\right)_{2} \cdot 6 \mathrm{H}_{2} \mathrm{O}$ (Alfa Aesar, >99.9\%), $\mathrm{Sr}\left(\mathrm{NO}_{3}\right)_{2}($ Merck, $>99.0 \%)$, and $\mathrm{Fe}\left(\mathrm{NO}_{3}\right)_{2} \bullet 9 \mathrm{H}_{2} \mathrm{O}($ Merck, $>98.0 \%)$ precursors were dissolved deionized water. Due to the different calcination temperature, the fuel and air electrode materials were impregnated separately. Firstly, the LCNT solution was impregnated onto the porous YSZ backbone, inside a cells' channel, by pipette until saturation, while the excess of the solution was removed with a cotton pad. After every impregnation cycle, the cells were placed in a furnace at $650^{\circ} \mathrm{C}$ to de-compose precursors. After achieving $50 \%$ by vol. of LCNT material, the cell was calcined at $1100{ }^{\circ} \mathrm{C}$ dwelled for $5 \mathrm{~h}$. Then, LSF was impregnated onto the outer layer, following the same way as LCNT to a final amount of $30 \mathrm{vol} \%$, and the final calcination temperature was $850{ }^{\circ} \mathrm{C}$ for $5 \mathrm{~h}$.

Microstructure analysis. The secondary electron images (SEI) were obtained using an FEI Scios electron microscope. The sample was mounted on the sample holder, and no gold coating was used for analysis.

Electrochemical test. Silver paste was used as the current collector and was applied to the whole area of electrodes. The as-prepared cell was mounted on a stainless steel tube, which provided hydrogen to the fuel electrode and sealed with Ceramic cement (Ceramabond 552, Aremco).

Electrochemical tests were carried out using Solartron 1255 Frequency Response Analyser, Solartron 1287 Electrochemical Interface, CorrWare v3.2c and ZPlot v3.2c 
software (Scribner Associates). The current-voltage (I-V) and the electrochemical impedance spectroscopy (EIS) were used to characterize cells' performance at a temperature range between $700{ }^{\circ} \mathrm{C}$ and $800{ }^{\circ} \mathrm{C}$ with $25^{\circ} \mathrm{C}$ intervals. The impedance spectra were taken in the $50000 \mathrm{~Hz}-0.25 \mathrm{~Hz}$ frequency range with the amplitude of excitation voltage equal to $20 \mathrm{mV}$. For a fuel cell operation, wet hydrogen $\left(3 \% \mathrm{H}_{2} \mathrm{O} / \mathrm{H}_{2}\right)$ was used as the fuel with a flow rate of $50 \mathrm{ml} / \mathrm{min}$, meanwhile ambient air was used as the gas for the oxygen electrode. Before electrochemical switching, the fuel electrode was reduced in a wet hydrogen atmosphere at $800^{\circ} \mathrm{C}$ for $1 \mathrm{~h}$. Then, the switching was applied at $800^{\circ} \mathrm{C}$ in a three-step process: 1 . The stair-step up to $2.1 \mathrm{~V}$ from the open-circuit voltage (OCV) with $40 \mathrm{mV} / 5 \mathrm{sec}$ potential step. 2. Electrochemical polling at $2.1 \mathrm{~V}$ for $2 \mathrm{~min}$. 3. The stair-step down to OCV from $2.1 \mathrm{~V}$ with $40 \mathrm{mV} / 5 \mathrm{sec}$ potential step.

The complex nonlinear least-squares (CNLS) approximation (13) was used for EIS analysis with the equivalent circuit, consisting of elements connected in series or parallel that correspond to individual electrode processes. The impedance spectra were fitted to the equivalent circuit using Z-view software. The rigs' ohmic resistance of $0.1 \Omega$ and inductance of $5.9 \times 10^{-6}$ were extracted from the impedance data.

\section{Results and Discussion}

\section{$\underline{\text { Structure of Tubular Cell }}$}

(a)

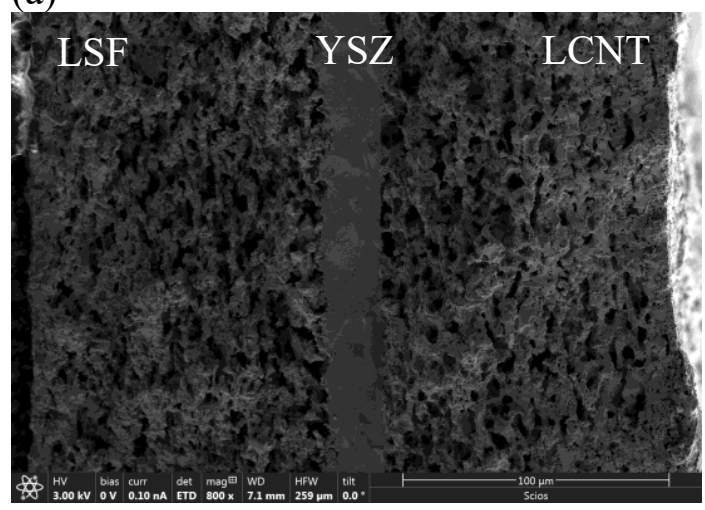

(b)

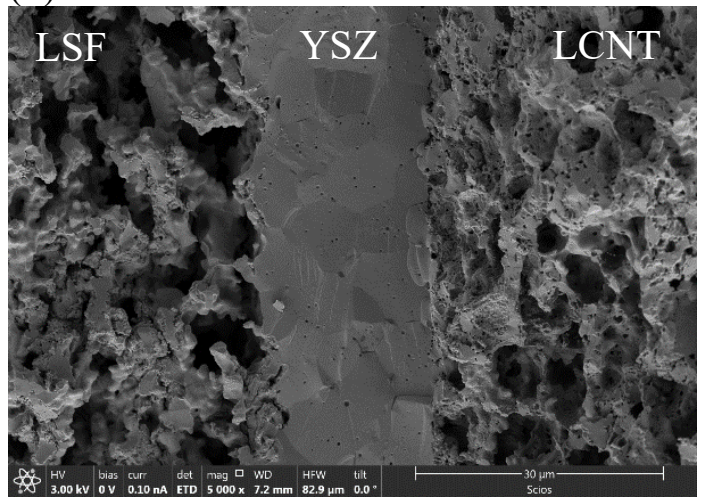

Figure 1. (a) - (b) SEM analysis of the tubular cell sintered at $1450{ }^{\circ} \mathrm{C}$ for $5 \mathrm{~h}$.

The SEM analysis of cells' cross-section (Figure 1) shows dens YSZ electrolyte, and only sparse closed pinholes are visible. The electrodes have good adhesion with YSZ electrolyte; no crack or delamination is visible in the cells' structure. The cell is double electrode supported, with an electrodes' thickness of about $100 \mu \mathrm{m}$ and a YSZ electrolyte of $20 \mu \mathrm{m}$.

The LSF impregnated oxygen electrode's microstructure is shown in Figure 2a, demonstrating the network of LSF nanoparticles formed on the YSZ surface. Such structure is advantageous in fuel cell operation as it increases the active area of LSF material and its TPB with YSZ (5). On the other side (Figure 2b), the impregnated LCNT perovskite creates a dense layer made of small grains covering the whole YSZ surface. In addition, nanoparticles are observed on the LCNT surface, which are believed to be Ni exsolving due to the electrochemical switching. Both impregnated materials are homogeneously 
distributed on the porous backbone structure, and porosity between $45-50 \%$ is achieved for the electrode after impregnation, assuring no diffusion losses during the cells' operation.

(a)

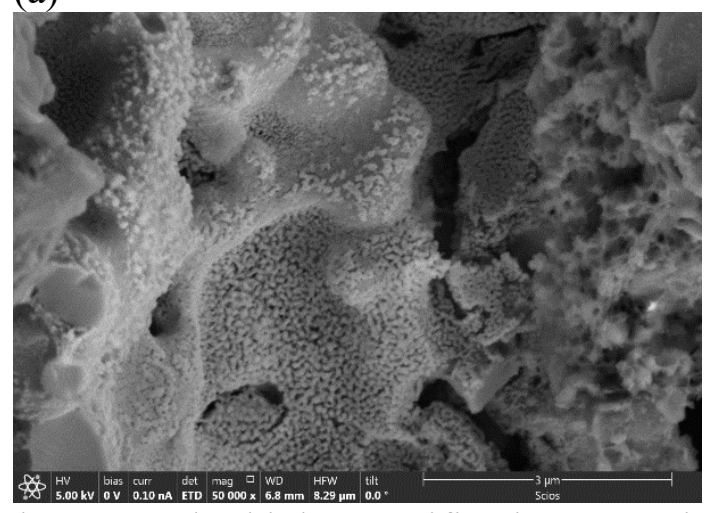

(b)

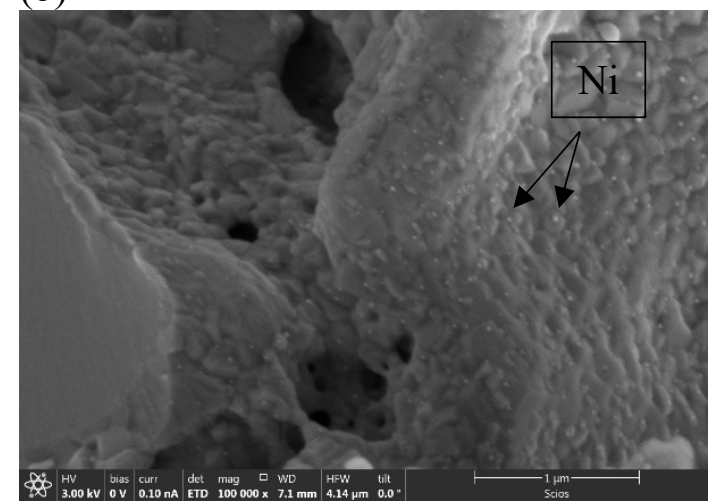

Figure 2. The high magnification SEM images of impregnated electrodes. (a) The LSF oxygen electrode. (b) The LCNT fuel electrode after switching.

\section{A process on the perovskite fuel electrode}

MIEC properties. One of the factors that perovskites owe their wide range of applications is the mixed ionic and electronic conductivity (MIEC). The ionic conduction in perovskites take place through oxygen vacancies $\left(\mathrm{V}_{\mathrm{O}}^{*}\right)$, therefore, their high concentration is desirable, both for oxygen and fuel electrode. In n-type conductors, the electronic conductivity takes place through $B$-site cation at various oxidation state $\left(\mathrm{B}_{\mathrm{B}}^{\prime} / \mathrm{B}_{\mathrm{B}}^{\mathrm{X}}\right)$, as electrons can move on cation with a higher charge on lower, through a conduction band.

For a given perovskite structure, the oxygen defect concentration is determined by oxygen partial pressure $\left(\mathrm{pO}_{2}\right)$. The $\mathrm{pO}_{2}$ in SOFC electrodes depends on the gas atmosphere and applied overpotential. In a low $\mathrm{pO}_{2}$ condition (reducing condition), lattice oxygen $\left(\mathrm{O}_{\mathrm{O}}^{\mathrm{X}}\right)$ in the perovskite will be stripped in the form of molecular oxygen, releasing electrons and producing oxygen vacancies $\left(\mathrm{V}_{\mathrm{O}}^{*}\right)$ in the corresponding site. The electrons would further reduce the $B$-site cation $\left(B_{B}^{X}\right)$ to a lower valence $\left(B_{B}^{\prime}\right)$ and move the overall reaction 1 to the right. Therefore, under a reducing environment, both ionic and electronic conductivity increase in n-type conductors.

$$
2 \mathrm{~B}_{\mathrm{B}}^{\mathrm{X}}+\mathrm{O}_{\mathrm{O}}^{\mathrm{X}} \leftrightarrow 2 \mathrm{~B}_{\mathrm{B}}^{\prime}+\mathrm{V}_{\mathrm{O}}^{*}+\frac{1}{2} \mathrm{O}_{2}
$$

Electrochemical switching. The switching procedure creates a high difference in electrochemical potential between the electrodes, leading to much lower $\mathrm{pO}_{2}$ on the fuel electrode side than during a chemical reduction. The ionic conductivity of LCNT will increase due to the creation of oxygen vacancies, while the generated electrons would reduce partial $\mathrm{Ti}^{4+}$ to $\mathrm{Ti}^{3+}$ and $\mathrm{Ni}^{2+}$ to $\mathrm{Ni}^{0}$. As reduction progresses, $\mathrm{Ni}$ nuclei will form and grow into Ni metal particles. Simultaneously, the formation of $\mathrm{Ti}^{4+} / \mathrm{Ti}^{3+}$ pairs increases the n-type conductivity of the oxide. The use of a sufficiently high $\mathrm{pO}_{2}$ makes this process partially not reversible; when the cell switches to the fuel cell mode (at higher $\mathrm{pO}_{2}$ potential), the $\mathrm{Ti}^{4+} / \mathrm{Ti}^{3+}$ pairs and $\mathrm{Ni}$ metal particles can retain in perovskite, improving fuel electrode properties, both in terms of conductivity and catalytical activity. 
The oxidation mechanism of $\mathrm{H}_{2}$ on switched perovskite electrodes. On MIEC perovskite surface, the $\mathrm{H}_{2}$ oxidation process involves both lattice oxygen $\left(\mathrm{O}_{\mathrm{O}}^{\mathrm{X}}\right)$ and $\mathrm{B}$-site cation $\left(\mathrm{B}_{\mathrm{B}}^{\mathrm{X}}\right)$, producing $\mathrm{H}_{2} \mathrm{O}$, oxygen vacancies $\left(\mathrm{V}_{\mathrm{O}}^{*}\right)$ and electrons associated with $\mathrm{B}$-site cation $\left(\mathrm{B}_{\mathrm{B}}^{\prime}\right)$, the reaction can be written in Kröger-Vink notation $(8,15)$ :

$$
\mathrm{H}_{2}(\mathrm{~g})+\mathrm{O}_{\mathrm{O}}^{\mathrm{X}}+2 \mathrm{~B}_{\mathrm{B}}^{\mathrm{X}}=\mathrm{H}_{2} \mathrm{O}(\mathrm{g})+\mathrm{V}_{\mathrm{O}}+2 \mathrm{~B}_{\mathrm{B}}^{\prime}
$$

This reaction will not proceed instantly but consists of multiple steps, starting with the diffusion of gases into the vicinity of active material, followed by the dissociative adsorption and transport of intermediate species for charge transfer reaction (8). Each of these steps has its own kinetic, which, apart from operational conditions (e.g. temperature, type and concentration of reactants, pressure, voltage), also depends on the properties and structure of the ceramic layers used in the cell (e.g. catalytic activity of electrodes, the electronic and ionic conductivity of materials, their thickness and microstructure).

The absorption/dissociation process is often the slowest step on perovskite electrodes (RDS). Before exsolution, only the MIEC surface take part in the adsorption step. Hydrogen could chemisorb on the MIEC absorption vacant site, which number among others depends on the concentration of oxygen-terminated surface sites, as during chemisorption, hydrogen bonds with oxygen (8). Likely, the process involves the two-step oxidative hydrogen dissociation to surface hydroxyl and water formation in the last step (15). Assuming that only Ti cation takes part in charge transfer reaction; the elementary steps on LCNT may look as follows:

$$
\begin{aligned}
& \mathrm{H}_{2}(\mathrm{~g})+\mathrm{O}_{\mathrm{O}}^{\mathrm{X}}+\mathrm{Ti}_{\mathrm{Ti}}^{\mathrm{X}}=\mathrm{OH}_{\mathrm{O}}^{\cdot}+\mathrm{H}_{\mathrm{ad}}(\mathrm{LCNT})+\mathrm{Ti}_{\mathrm{Ti}}^{\prime} \\
& \mathrm{H}_{\mathrm{ad}}(\mathrm{LCNT})+\mathrm{O}_{\mathrm{O}}^{\mathrm{X}}+\mathrm{Ti}_{\mathrm{Ti}}^{\mathrm{X}}=\mathrm{OH}_{\mathrm{O}}^{\cdot}+\mathrm{Ti}_{\mathrm{Ti}}^{\prime} \\
& 2 \mathrm{OH}_{\mathrm{O}}^{\cdot}=\mathrm{O}_{\mathrm{O}}^{\mathrm{X}}+\mathrm{H}_{2} \mathrm{O}(\mathrm{g})+\mathrm{V}_{\mathrm{O}}
\end{aligned}
$$

The perovskite, particularly oxygen-deficient and with low ionic conductivity, may have low availability of sites for $\mathrm{H}_{2}$ chemisorption. However, Ni metal nanoparticles have a very high catalytic activity towards $\mathrm{H}_{2}$ adsorption and dissociation (7), making the perovskite with Ni exsolution exhibit improved performance. In this case, hydrogen will absorb and dissociate to hydrogen species on the Ni and diffuse to the LCNT surface, bypassing the step described by reaction 3 (15).

$$
H_{2}(g)=2 H_{a d}(N i)
$$


(a)

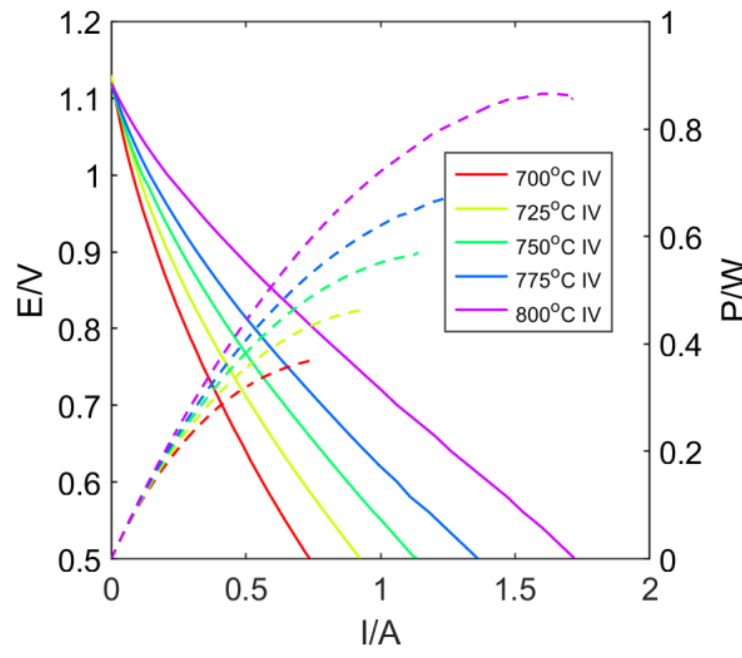

(c)

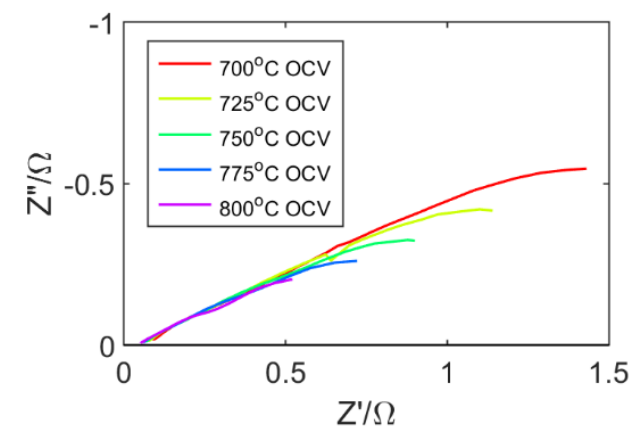

(e)

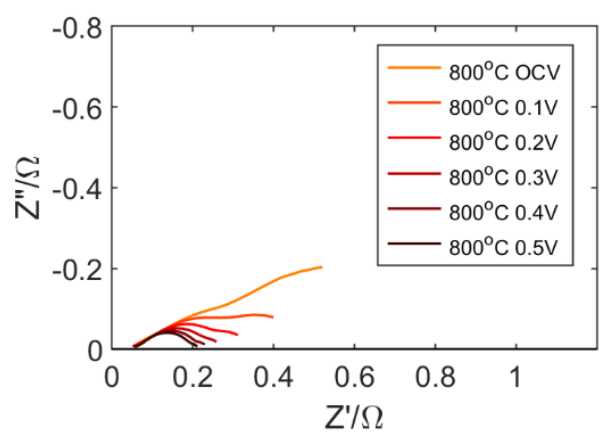

(b)

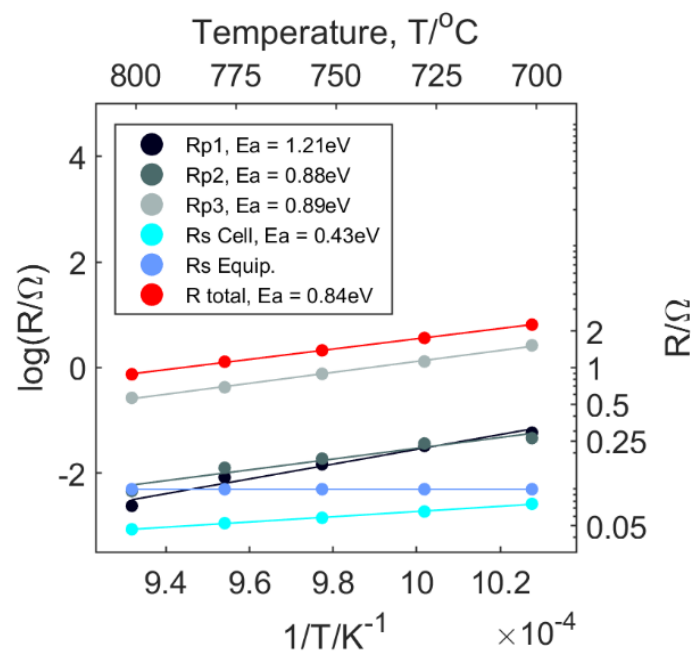

(d)

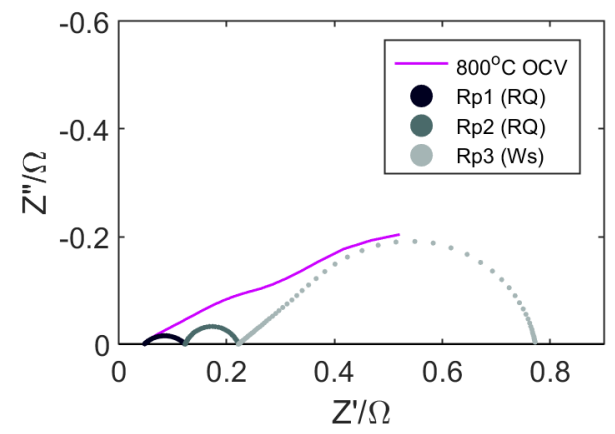

(f)

$\mathrm{E}_{\mathrm{OCV}} \mathrm{E}_{\mathrm{DC}} \mathrm{N}$

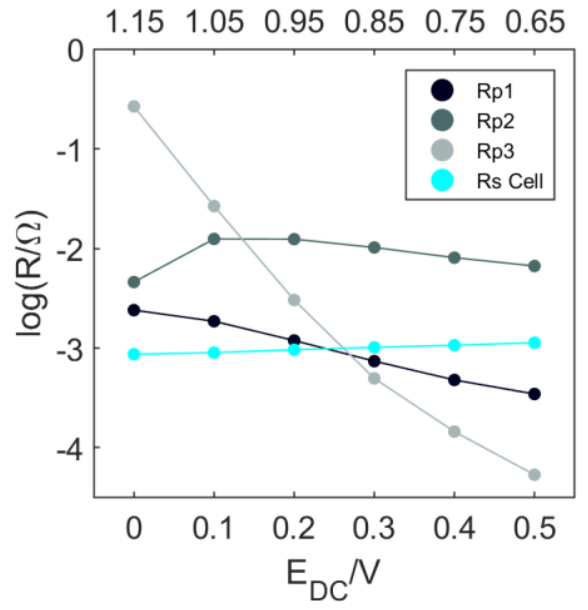

Figure 3. Electrochemical test of the tubular cell after switching. (a) I-V curve of cell operating in fuel cell mode at various temperature. (b) Arrhenius plot of cells' resistance at OCV. (c) EIS analysis at OCV at different temperature. (d) The equivalent circuit used for cells' analysis at $800^{\circ} \mathrm{C}$. (e) EIS analysis at changing voltage at $800^{\circ} \mathrm{C}$ in fuel cell mode. (f) The polarisation and ohmic resistance of the fuel cell operation at various voltage steps at $800^{\circ} \mathrm{C}$. 
The open-circuit voltage (OCV) of the tubular cell after switching at $700-800{ }^{\circ} \mathrm{C}$ was above $1.1 \mathrm{~V}$ at the whole temperature range, suggesting a good tightness of the cell (Figure $3 \mathrm{a}$ ). Interestingly, the I-V curve slope decreases, indicating an improvement of electrode kinetics at the higher voltage. The maximum power density decrease from $0.87 \mathrm{~W}$ at $800{ }^{\circ} \mathrm{C}$ at $0.6 \mathrm{~V}$ to $0.35 \mathrm{~W}$ at $700{ }^{\circ} \mathrm{C}$.

The impedance analysis (EIS) made at OCV shows the kinetics of individual steps of $\mathrm{H}_{2}$ oxidation at various temperature (Figure $3 \mathrm{c}$ ). Processes that take part in cell operation have different kinetics, measured by relaxation time in a given frequency range. The faster processes of charge transfer could be visible at a higher frequency. In comparison, slower processes, like diffusion or surface reaction, have longer relaxation time and are triggered at a lower frequency range. The equivalent circuit adopted for EIS shown in Figure $3 \mathrm{~d}$ consists of ohmic resistance Rs and three polarisation processes Rp1, Rp2 and Rp3. Rp1 and Rp2 were modelled by semicircles (resistance and constant phase element connected in parallel), while Rp3 by the Warburg element. Figure $3 b$ shows the Arrhenius Plot of ohmic resistance of cell and rig and the cells' polarisation resistance, calculated from the equivalent circuit. All cells' polarisation resistance follows Arrhenius dependence, meaning they are thermally activated; thus, the activation energy Ea could be calculated from the lines' slope. It is accepted here that the cells' polarisation mainly comes from the LCNT impregnated fuel electrode. The symmetrical tubular oxygen electrode cell was analyzed separately (not shown). One oxygen electrode layer showed a minimal value of the polarisation resistance of around $0.02 \Omega$ at $800{ }^{\circ} \mathrm{C}$, located at a very high frequency.

The cells' ohmic resistance (Rs) calculated from equivalent circuit increases from $0.0478 \Omega$ at $800{ }^{\circ} \mathrm{C}$ to $0.0758 \Omega$ at $700{ }^{\circ} \mathrm{C}$. Rs is the sum of electrolyte resistance and both electrodes after extraction of rigs' resistance which is about $0.1 \Omega$. Most likely, cells' ohmic resistance comes mainly from thick $100 \mu \mathrm{m}$ electrode layers rather than the $20 \mu \mathrm{m}$ electrolyte. In general, the Rs minimally contributes to the total resistance. The total polarisation resistance at $\mathrm{OCV}$ increases from $0.73 \Omega$ at $800{ }^{\circ} \mathrm{C}$ to $2.08 \Omega$ at $700{ }^{\circ} \mathrm{C}$. The $\mathrm{Rp} 3$ is the main contribution to the polarisation resistance with a value of $0.56 \Omega$ at $800{ }^{\circ} \mathrm{C}$ and a characteristic frequency of $0.1 \mathrm{~Hz}$. The Rp1 and Rp2 both have a low value of $0.07 \Omega$ and $0.1 \Omega$ and characteristic frequency of $182 \mathrm{~Hz}$ and $6.5 \mathrm{~Hz}$ at $800{ }^{\circ} \mathrm{C}$, respectively.

Figure 3e shows the EIS analysis of the tubular cell operating at the various potential in fuel cell mode after the switching procedure. The data were fitted according to the proposed equivalent circuit, and the ohmic and polarisation resistance were plotted against the applied potential (Figure 3f). The EIS at varied potential gives some insight into the I-V behaviour that the improved characteristic at higher potential is likely due to the reduction of Rp3. According to LCNT defect chemistry, the anodic polarisation would move reaction 1 to the left, resulting in the filling of oxygen vacancies by oxygen ions conducted from electrolyte and oxidation of $\mathrm{Ti}^{3+}$ to $\mathrm{Ti}^{4+}$. The oxidation of $\mathrm{Ti}^{3+}$ will lead to a drop in the electronic conductivity; indeed, EIS data shows an increase in ohmic resistance (Figure 3e - f). The reduction of Rp3 could be explained by the decrease of oxygen vacancies due to the incorporation of oxide ions in the LCNT perovskite lattice under applied potential, thus increasing the number of adsorption sites for $\mathrm{H}_{2}$. Perhaps the number of exsolved $\mathrm{Ni}$ nanoparticles is too low to dissociate hydrogen in reaction 6; therefore, it is supplemented by reaction 3 on a perovskite surface that runs faster at the higher potential due to the higher availability of oxygen terminated sites. The second explanation is that the Ni catalyst 
amount is sufficient, but the perovskite surface is deficient in the number of oxygen sites for reaction with already dissociated hydrogen (reaction 4).

(a)

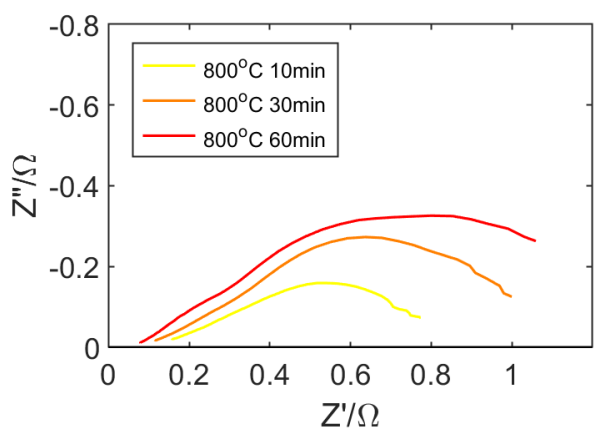

(c)

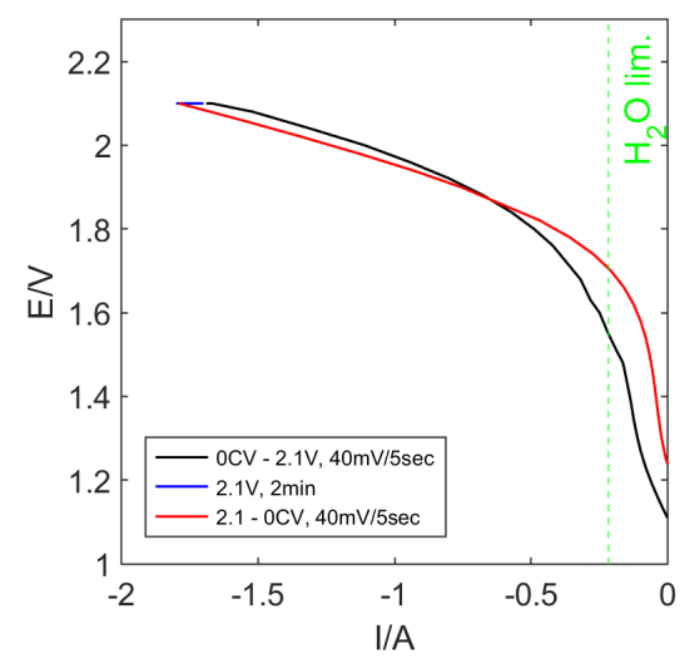

(b)

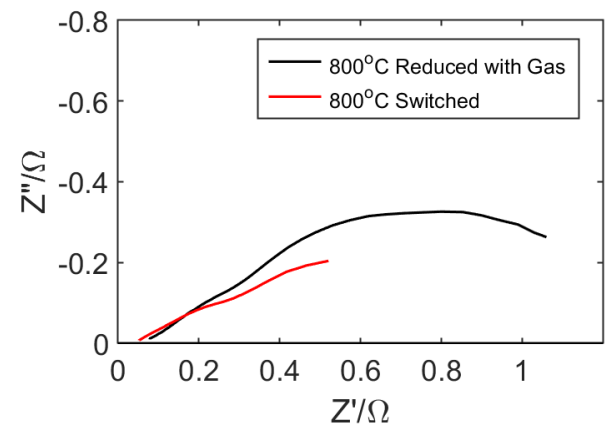

(d)

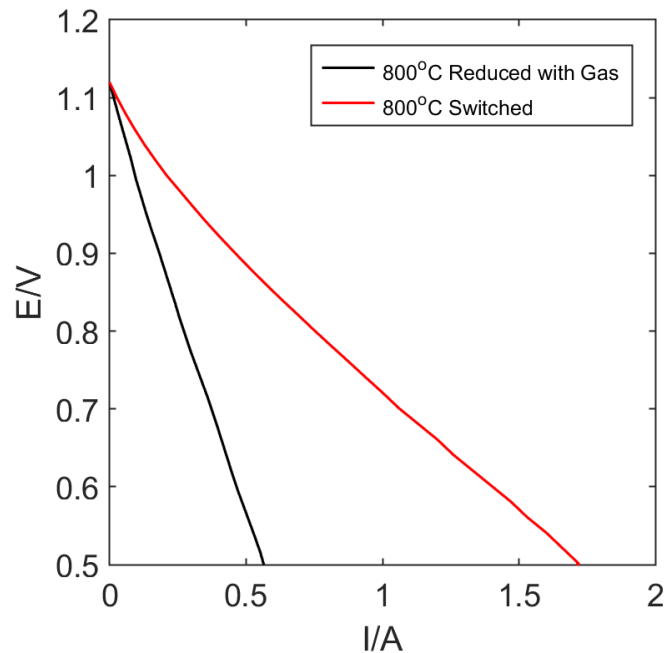

Figure 4. Electrochemical test of the tubular cell with the chemical reduction and electrochemical switching. (a) - (b) EIS analysis at OCV during a chemical reduction in 3\% $\mathrm{H}_{2} \mathrm{O} / \mathrm{H}_{2}$. (e) I-V characteristic of the cell during switching. (f) I-V characteristic of the cell after a chemical reduction and switching.

Figure $4 \mathrm{a}$ shows the tubular cells' EIS characteristic during a chemical reduction in wet $\mathrm{H}_{2}\left(3 \% \mathrm{H}_{2} \mathrm{O} / \mathrm{H}_{2}\right)$. After the reduction for about one hour, the EIS stabilized and presumably, the electrode material was in equilibrium, or close to, with gas atmosphere. During the process, the Rs and Rp1 decrease, while Rp2 and especially Rp3 increase. It seems that the chemical reduction gave rise to the passivation phenomenon that changes the perovskite surface properties, leading to the lower number of active sites for $\mathrm{H}_{2}$ adsorption, at least at OCV conditions. During the process, the absorption sites on the oxygen sites would be gradually filled by hydrogen. Perhaps, if the conversion of absorbed hydrogen to water is sluggish, either due to poor exchange of oxide ions or electrons within the material or slow desorption coefficient, part of the adsorption sites would be blocked by the hydroxyl ions itself; thus, polarisation resistance will increase, as it is in this case.

Figure $4 \mathrm{~b}$ shows the EIS analysis at OCV of the cell after the switching procedure. All resistive contribution seems to be reduced; however, unlike after chemical reduction, Rp3 
also decreased. Figure $4 \mathrm{c}$ shows the I-V characteristic of the cell during the switching procedure. The curve has a large slope up to around $-0.2 \mathrm{~A}$, then the amount of used current increase. Cell operate at $3 \% \mathrm{H}_{2} \mathrm{O} / \mathrm{H}_{2}$ at $50 \mathrm{ml} / \mathrm{min}$; for such composition, the maximum current that can be achieved for $\mathrm{H}_{2} \mathrm{O}$ reduction is $0.215 \mathrm{~A}$; the value coincidence with the location of slopes' change, exposing different reaction kinetics. The current above this limit must also be utilized to reduce LCNT material, and more strictly, reduce Ti and Ni ions and generation of oxygen vacancies. Figure $4 d$ shows the I-V characteristic of the cell after gas reduction and switching procedure. After switching, three times more current is generated at $0.5 \mathrm{~V}$ in fuel cell mode. Both curves seem to decrease their slope at a higher current; but, the switched cell to a higher degree.

\section{Conclusion}

The manufacturing method based on co-casting and impregnation was developed for tubular SOFC manufacturing. The $20 \mu \mathrm{m}$ YSZ electrolyte and two supporting entirely ceramic $100 \mu \mathrm{m}$ electrodes did not significantly contribute to cells' total resistance. The electrochemical analysis indicates that the cells' activity is mainly influenced by sluggish adsorption/dissociation kinetics on the perovskite surface. The adsorption/dissociation kinetics were improved after switching due to $\mathrm{Ti}^{4+}$ reduction, generation of vacant oxygen sites and Ni exsolution.

\section{Acknowledgements}

The authors would like to acknowledge the EPSRC and the University of St Andrews for funding this work.

\section{References}

1. H. Zeng, K. Nowicki, J. T. S. Irvine, Y. Shia, and N. Cai, ECS Trans., 91(1), 447 (2019).

2. K. Nowicki, H. Zeng, and J. T. S. Irvine, ECS Trans., 91(1), 139 (2019).

3. F. G. E. Jones, P. A. Connor, and J. T. S. Irvine, Proc. of 8th International Solid Oxide Fuel Cell, 1082 (2003).

4. H. Wang, Z. Gao, and S. A. Barnett, J. Electrochem. Soc., 163, F196 (2016).

5. J. M. Vohs, and R. J. Gorte, Adv. Mater., 21, 943 (2009).

6. V. Vashook, L. Vasylechko, N. Trofimenko, M. Kuznecov, P. Otchik, J. Zosel, U. Guth, J. Alloys Compd. 419, 271 (2006).

7. S. Primdahl, and M. Mogensen, Solid State Ionics 152-153, 597 (2002).

8. T. Zhu, D. E. Fowler, K. R. Poeppelmeier, M. Han, and S.A. Barnett, J. Electrochem. Soc. 163, F952 (2016).

9. H. Zhu, R. J. Kee, V. M. Janardhanan, O. Deutschmann, and D. G. Goodwin, J. Electrochem. Soc. 152, A2427 (2005).

10. D. Neagu, T. S. Oh, S. Tae, D. N. Miller, H. Ménard, S. M. Bukhari, S. R. Gamble, R. J. Gorte,J. M. Vohs, J. T.S. Irvine, Nat. Commun. 6, (2015).

11. J. H. Myung, D. Neagu, D. N. Miller, and J. T. S. Irvine, Nature 537, 528 (2016). 
12. R. E. Mistler and E. R. Twiname, Tape Casting: Theory and Practice. WileyAmerican Ceramic Society, (2000).

13. B. Boukamp, Sol. State. Ion. 20, 31 (1986).

14. T. Sik. Oh, E. K. Rahani, D. Neagu, J. T. S. Irvine, V. B. Shenoy, R. J. Gorte, and J. M. Vohs, Phys. Chem. Lett. 6, 5106 (2015).

15. A. K. Opitz, A. Nenning, V. Vonk, S. Volkov, F. Bertram, H. Summerer, S. Schwarz, A. S. Thirsfeld, J. Bernardi, A. Stierle, and J. Fleig, Nat. Commun. 11, 1 (2020). 